\title{
ANALISIS KARBON TERSIMPAN PADA LAMUN Enhalus acoroides DI PERAIRAN PACIRAN, KECAMATAN PACIRAN, KABUPATEN LAMONGAN
}

\author{
Eva Falantika Ndari ${ }^{\mathrm{a}}$, Aida Sartimbul ${ }^{\mathrm{a}, *}$, Citra Satrya Utama Dewi ${ }^{\mathrm{a}}$ \\ ${ }^{a}$ Ilmu Kelautan, Fakultas Perikanan dan Ilmu Kelautan, Universitas Brawijaya, \\ Jl. Veteran No 1. Malang. 65145. Indonesia \\ *Koresponden penulis : aida@ub.ac.id
}

\begin{abstract}
Abstrak
Pemanasan global merupakan fenomena yang menjadi perhatian sejak masa pra-industri. Konsentrasi gas $\mathrm{CO}_{2}$ yakni sekitar 280 ppm hingga 379 ppm pada 2005. Pengetahuan masyarakat mengenai kemampuan penyerapan $\mathrm{CO}_{2}$ yang tersimpan pada lamun dalam bentuk biomassa, dapat menjadi langkah awal dalam mitigasi perubahan iklim melalui pengurangan kadar $\mathrm{CO}_{2}$ di atmosfer. Fungsi ekologi lamun terdapat di Pantai Paciran, Lamongan yang salah satunya sebagai penyerap $\mathrm{CO}_{2}$ di atmosfer, masih perlu adanya data akan potensi tersebut. Untuk itu, penulis melakukan penelitian dengan Judul Analisis Karbon Tersimpan Pada Lamun Enhalus acoroides Di Pantai Paciran, Kecamatan Paciran, Kabupaten Lamongan, bertujuan mengetahui luasan penutupan, kerapatan, jumlah biomassa, dan total karbon yang terdapat di Pantai Paciran, Kabupaten Lamongan. Penelitian ini dilakukan pada Juni 2017 yang berlokasi di perairan Pantai Paciran, Kecamatan Paciran, Kabupaten Lamongan dengan kondisi lamun yang membentuk kelompok-kelompok atau tidak merata. Penghitungan biomassa dan karbon pada lamun dilakukan di Laboratorium Ekologi, Fakultas MIPA Universitas Brawijaya dengan menerapkan metode Loss on Ignition. Kondisi penutupan lamun di Pantai Paciran termasuk dalam kategori baik karena ketiga stasiun memiliki nilai penutupan

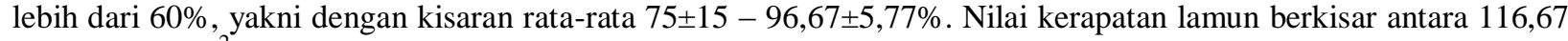
- 216,67 ind $/ \mathrm{m}^{2}$ sehingga kondisi tersebut termasuk pada kategori Rapat hingga Sangat Rapat. Biomassa lamun tertinggi mencapai $1859 \mathrm{gbk} / \mathrm{m}^{2}$ dan terendah yakni 1101,03 gbk/ $\mathrm{m}^{2}$. Jumlah karbon pada lamun dengan nilai tertinggi sebesar $246,99 \mathrm{gC} / \mathrm{m}^{2}$ sedangkan yang terendah sebesar $145,58 \mathrm{gC} / \mathrm{m}^{2}$.
\end{abstract}

Kata Kunci: Biomassa, $\mathrm{CO}_{2}$, Enhalus acoroides, Pemanasan Global

\begin{abstract}
Global warming is a phenomenon that has beeen a concern since pre-industrial times. The concentration of $\mathrm{CO}_{2}$ gas is around 280 ppm to 379 ppm in 2005. Public knowledge about the ability to absorb $\mathrm{CO}_{2}$ stored in seagrasses in the form of biomass, can be the first step in mitigating climate change through reducing $\mathrm{CO}_{2}$ levels in the atmosphere. Seagrass ecological function is found in Paciran Waters, Lamongan, one of which is as an atmospheric $\mathrm{CO}_{2}$ absorber, there is still a need for data on this potential. For this reason, the authors conducted a study with the title of Stored Carbon Analysis on Enhalus acoroides Seagrass at Paciran Waters, Paciran District, Lamongan Regency, aimed to find out the coverage area, density, amount of biomass, and total carbon contained in Paciran Waters, Lamongan Regency. This research was conducted in June 2017 which is located in Paciran Waters, Paciran District, Lamongan Regency with seagrass conditions that form groups or are not evenly distributed. Calculation of biomass and carbon in seagrasses is carried out at the Ecology Laboratory, Faculty of Mathematics and Natural Sciences, Brawijaya University by applying the method of Loss On Ignition. Seagrass coverage conditions at Paciran Waters are in good category because the three stations have a closing value of more than $60 \%$, with an average range of $75 \pm 15-96.67 \pm 5.77 \%$. The value of seagrass density ranged from 116.67 to $216.67 \mathrm{ind} / \mathrm{m}^{2}$ so that the condition was included in the Dense until Very Dense category. The highest seagrass biomass reached $1859 \mathrm{~g} / \mathrm{m} 2$ and the lowest was $1101.03 \mathrm{~g} / \mathrm{m}^{2}$. The amount of carbon in seagrass with the highest value is $246.99 \mathrm{gC} / \mathrm{m}^{2}$ while the lowest is $145.58 \mathrm{gCl} \mathrm{m}^{2}$.
\end{abstract}

Keywords: Biomass, $\mathrm{CO}_{2}$, Enhalus acoroides, Global Warming 


\section{PENDAHULUAN}

Pemanasan global merupakan fenomena yang menjadi perhatian sejak masa pra-industri. Konsentrasi gas $\mathrm{CO}_{2}$ yakni sekitar $280 \mathrm{ppm}$ hingga 379 ppm pada 2005[1]. Hal ini dikarenakan, $\mathrm{CO}_{2}$ merupakan gas rumah kaca yang saat ini kandungannya meningkat lebih cepat dibanding gas rumah kaca lain[2].

Lamun dapat hidup secara berkelompok baik dengan lamun yang memiliki jenis sama dan membentuk padang lamun homogen, maupun dengan lamun jenis lain yang membentuk padang lamun heterogen[3]. Lamun merupakan tumbuhan sejati satu-satunya yang mampu hidup di kolom perairan, oleh karena itu, lamun memiliki potensi yang besar untuk menyerap $\mathrm{CO}_{2}$ selama proses fotosintesisnya berlangsung. Pengetahuan mengenai kemampuan penyerapan $\mathrm{CO}_{2}$ yang tersimpan oleh lamun dalam bentuk biomassa (above ground dan below ground), dapat menjadi langkah awal dalam mitigasi perubahan iklim melalui pengurangan kadar $\mathrm{CO}_{2}$ di atmosfer.

Beberapa studi yang telah mengkaji masalah ini dilakukan di luar Jawa Timur, misalnya di Pantai Sanur[4] dan Tanjung Lesung, Banten[5]. Oleh karena itu, perlu dilakukan studi di daerah utara Jawa Timur tepatnya di Kecamatan Paciran, Lamongan, karena selain pada lokasi tersebut studi ini belum dilakukan, keberadaan lamun Enhalus acoroides di daerah utara Jawa Timur masih hanya ditemukan di Lamongan khususnya di Kecamatan Paciran. Tujuan dari penelitian ini untuk mengetahui nilai penutupan, nilai kerapatan, jumlah biomassa dan karbon yang dapat diserap Enhalus acoroides per satuan luas.

\section{BAHAN DAN METODE}

Penelitian ini dilaksanakan pada Juni 2017, di Perairan Paciran, Kecamatan Paciran, Kabupaten Lamongan. Pengambilan data kerapatan dan penutupan dilakukan di Perairan Paciran dan analisis data lainnya dilakukan di Laboratorium. Adapun titik stasiun lokasi penelitian tersaji pada Gambar 1.

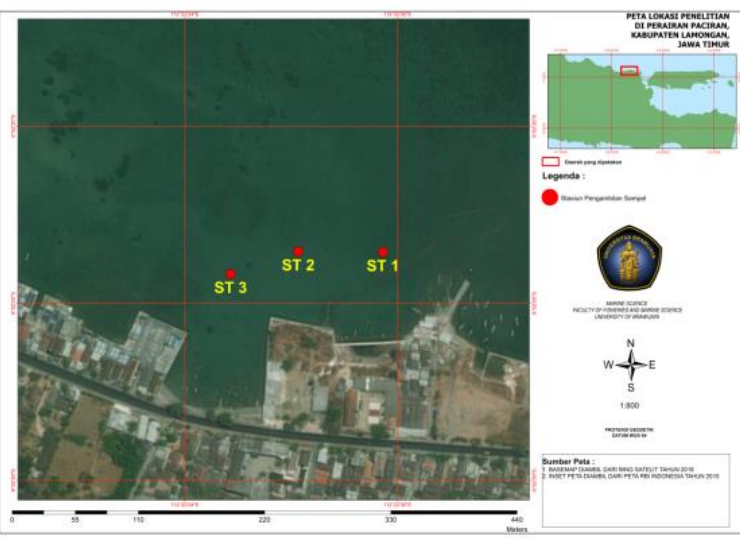

Gambar 1. Titik Lokasi Pengambilan Sampel

Titik koordinat stasiun lokasi pengambilan sampel dapat dilihat pada Tabel 1.

Tabel 1. Koordinat Stasiun Pengambilan Sampel

\begin{tabular}{cc}
\hline Stasiun & Koordinat \\
\hline 1 & S $6.872961^{\circ}-$ E $112.374858^{\circ}$ \\
2 & S $6.872975^{\circ}-$ E $112.374103^{\circ}$ \\
3 & S $6.873156^{\circ}-$ E $112.373622^{\circ}$ \\
\hline
\end{tabular}

\section{Pengambilan Sampel Lamun}

Pada penelitian ini diterapkan metode purposive sampling dan dibuat 3 stasiun yang berjarak 50 - 80m.Pada setiap stasiun masingmasing dipasang satu transek garis secara tegak lurus terhadap garis pantai dan terdiri atas tiga transek kuadran yang dipasang dengan jarak kurang lebih 5m.Pencuplikan lamun Enhalus acoroides dilakukan untuk proses selanjutnya.

\section{Nilai Penutupan Lamun}

Nilai penutupan lamun diperoleh dengan menilai secara visual persentase penutupannya. Luasan yang digunakan untuk penghitungan nilai penutupan ialah $50 \times 50 \mathrm{~cm}$. Setelah dilakukan penilaian, hasil tersebut dibandingkan atau digolongkan dengan mengacu pada penggolongan kategori[6] yang tersaji pada Tabel 1 .

Tabel 1. Kategori Kondisi Penutupan Lamun oleh KEPMEN LH

\begin{tabular}{ccc}
\hline & Kondisi & Penutupan \\
\hline Baik & Kaya / Sehat & $\geq 60$ \\
\hline Rusak & $\begin{array}{c}\text { Kurang Kaya / } \\
\text { Kurang Sehat }\end{array}$ & $30-59,9$ \\
\hline
\end{tabular}




\begin{tabular}{cc}
\hline Kondisi & Penutupan \\
\hline Miskin & $\leq 29,9$ \\
\hline
\end{tabular}

\section{Kerapatan Lamun}

Penghitungan jumlah tegakan lamun pada transek dilakukan untuk mengetahui kerapatan lamun (N). Setelah diketahui jumlahnya kemudian dihitungmenggunakan rumus sebagai berikut [7]:

$$
\mathrm{Di}=\frac{\mathrm{N}}{\mathrm{A}}
$$

Keterangan:

Di : Kerapatan jenis (tegakan $/ \mathrm{m}^{2}$ )

$\mathrm{N}$ : Jumlah tegakan

A : Luas area penghitungan sampel

\section{Biomassa dan Konsentrasi Karbon Lamun}

Pengambilan sampel biomassa dilakukan yang kemudian dipisahkan daun, rhizomadan akarnya kemudian dikeringkan dengan cara dioven dalam suhu tertentu.

Penghitungan nilai konsentrasi karbon lamun yang dinyatakan dalam satuan gram berat kering per meter persegi $\left(\mathrm{gbk} / \mathrm{m}^{2}\right)$, dipisahkan perjaringan dilakukan dengan menerapkan metode Loss on Ignitionmenggunakan alat Furnace yang dilakukan di Laboratorium Ekologi Fakultas MIPA Universitas Brawijaya. Adapun rumusrumus yang digunakan dalam perhitungan konsentrasi karbon antara lain rumus untuk menghitung kadar abu [8].

$$
\text { Kadar } \mathrm{Abu}=\left(\frac{\mathrm{c}-\mathrm{a}}{\mathrm{b}-\mathrm{a}}\right) \times 100 \%
$$

Langkah selanjutnya ialah menghitung jumlah bahan organik, yaitu dengan rumus:

$$
\text { Kadar Bahan Organik }=\frac{((b-a)-(c-a))}{(b-a)} \times 100 \%
$$

Setelah didapatkan hasilnya, kemudian dihitung menggunakan rumus:

$$
\text { Kandungan karbon }=\frac{\text { Bahan Organik }}{1,724}
$$

Keterangan: a: berat cawan

$$
\begin{aligned}
& \text { b: berat cawan }+ \text { berat sampel } \\
& \text { c: berat }(\text { cawan }+ \text { abu })
\end{aligned}
$$

\section{1,724: konstanta nilai bahan organik}

Angka 1/1,724 merupakan angka umum yang digunakan untuk menghubungkan bahan organik dengan karbon [9].

\section{HASIL DANPEMBAHASAN}

\section{Nilai Penutupan Lamun}

Nilai penutupan lamun dipengaruhi oleh nilai kerapatan lamun, yaitu semakin tinggi kerapatan, maka nilai penutupannya juga akan semakin tinggi. Pada Stasiun 1 nilai rata-rata persentase penutupan lamun sebesar $80 \pm 10 \%$.Pada Stasiun 2 didapatkan nilai persentase terendah dari ketiga stasiun yakni sebesar $75 \pm 15 \%$. Nilai penutupan ini berbanding lurus dengan nilai kerapatan lamun. Pada Stasiun 3 memiliki nilai rata-rata persentase tertinggi, yaitu sebesar $96,67 \pm 5,77 \%$.

Pada ketiga stasiun tersebut dapat menunjukkan bahwa penutupan lamun berada pada kategori baik, karena ketiga stasiun tersebut memiliki persentase penutupan sebesar $>60 \%$.kondisi nutrien yang terdapat pada masingmasing stasiun memengaruhi nilai penutupan.Adapun grafik nilai penutupan lamun pada ketiga stasiun tersaji pada Gambar 2.

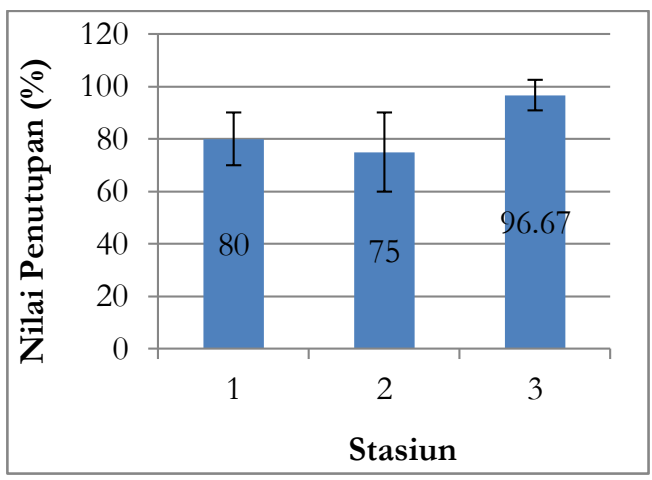

Gambar 2. Nilai Penutupan Lamun Pada Stasiun1, 2, dan 3 dengan nilai tertinggiterletak pada Stasiun 3.

\section{Kerapatan Lamun}

Kerapatan lamun ialah parameter untuk mengukur jumlah individu lamun yang dihitung dalam setiap satuan luas meter persegi 
(individu/ $\mathrm{m}^{2}$ )[4]. Hasil penghitungan kerapatan lamun Enhalus acoroides tersaji dalam Gambar 3.

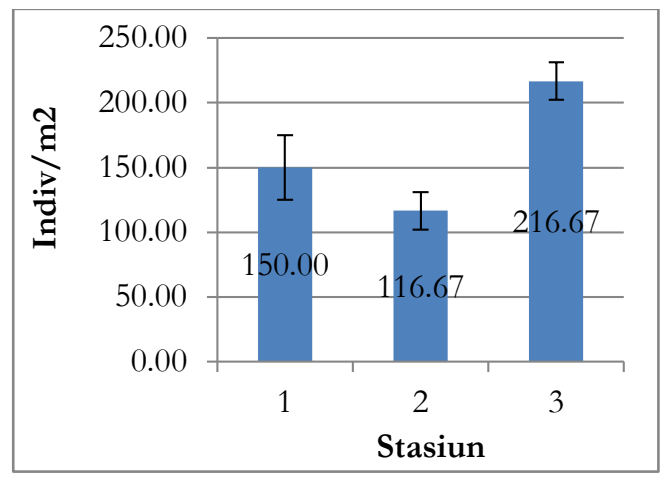

Gambar 3. Nilai Kerapatan Lamun PadaStasiun 1, 2 dan 3 dengan nilaikerapatan tertinggi pada Stasiun 3

Kerapatan ketiga stasiun berada pada kisaran $116,67 \pm 14,43-216,67 \pm 14,43 \mathrm{ind} / \mathrm{m}^{2}$. Stasiun yang memiliki kerapatan terendah ialah pada Stasiun 2, yakni dengan nilai kerapatan sebesar 116,67 $\pm 14,43 \mathrm{ind} / \mathrm{m}^{2}$, sedangkan Stasiun yang memiliki kerapatan tertinggi ialah Stasiun 3, dimana stasiun tersebut memiliki nilai kerapatan $216,67 \pm 14,43 \mathrm{ind} / \mathrm{m}^{2}$. Pada Stasiun 1 memiliki nilai kerapatan sebesar $150 \pm 25,00 \mathrm{ind} / \mathrm{m}^{2}$. Kondisi substrat dan kondisi perairan memengaruhi pertumbuhan lamun.

Kondisi tersebut menggambarkan bahwa kerapatan lamun memiliki nilai yang tinggi atau dapat dikatakan bahwa kondisinya Rapat, bahkan di salah satu stasiun memiliki kondisi Sangat Rapat. Penilaian kondisi ini mengacu pada Skala kondisi oleh Braun-Blanquer [10] yang tersaji pada Tabel 2.

Tabel 2. Skala Kondisi Kerapatan Lamun

\begin{tabular}{ccc}
\hline $\begin{array}{c}\text { Skala Kondisi } \\
\text { (ind/m2) }\end{array}$ & Kerapatan & Kondisi \\
\hline 5 & $>175$ & Sangat Rapat \\
4 & $125-175$ & Rapat \\
3 & $75-125$ & Agak Rapat \\
2 & $25-75$ & Jarang \\
1 & $<25$ & Sangat Jarang \\
\hline
\end{tabular}

\section{Biomassa lamun}

Pada Stasiun 1 diperoleh jumlah biomassa lamun yakni sebesar $1672,50 \mathrm{gbk} / \mathrm{m}^{2}$ yang terdiri atas berat biomassa pada daun / above ground sebesar $442,50 \mathrm{gbk} / \mathrm{m}^{2}$ dan bagian below ground sebesar $1230 \mathrm{gbk} / \mathrm{m}^{2}$. Pada Stasiun 2 diperoleh jumlah biomassa sebesar $1101,03 \mathrm{gbk} / \mathrm{m}^{2}$, yang terdiri atas berat bagian above ground sebesar $392,00 \mathrm{gbk} / \mathrm{m}^{2}$ dan bagian below ground sebesar $709,33 \mathrm{gbk} / \mathrm{m}^{2}$. Pada Stasiun 3 jumlah biomassanya sebesar $1859 \mathrm{gbk} / \mathrm{m}^{2}$ yang terdiri atas bagian above ground sebesar $626,17 \mathrm{gbk} / \mathrm{m}^{2}$ dan bagian below ground $1232,83 \mathrm{gbk} / \mathrm{m}^{2}$.

Jumlah biomassa yang paling rendah terdapat pada Stasiun 2, kondisi tersebut disebabkan karena jumlah penutupan dan kerapatan yang terdapat pada Stasiun 2 memiliki nilai yang paling rendah. Grafik jumlah biomassa lamun pada ketiga stasiun tersaji pada Gambar 4.

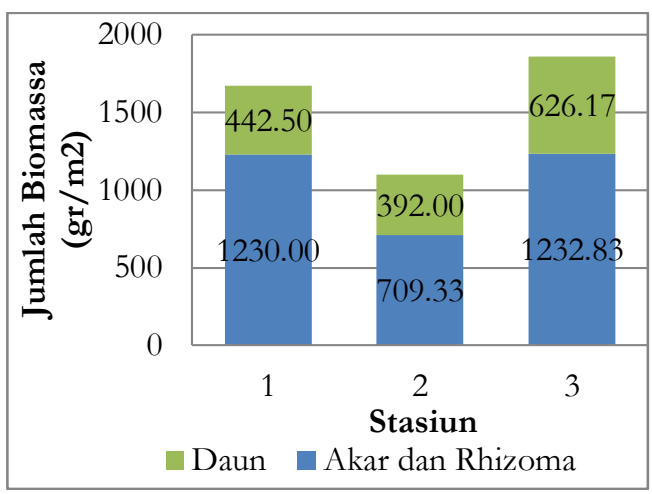

Gambar 4. Jumlah biomassa lamun E. acoroidespada ketiga stasiun yang dihitungdalam satuan Gram Berat $\operatorname{Kering}(\mathrm{GBK}) / \mathrm{m}^{2}$.

Biomassa yang terdapat pada bagian bawah substrat memiliki nilai atau jumlah yang lebih besar dibandingkan dengan biomassa di atas substrat, menjadi kondisi umum terutama pada lamun yang memiliki bagian tubuh berkayu. Hal ini didukung oleh pernyataan[5] yang menyatakan bahwa biomassa yang terdapat di bawah substrat seringkalimendominasi berat keseluruhan biomassa lamun. Hal tersebut dikarenakan materi yang terbentuk pada bagian bawah substrat memiliki tekstur yang lebih padat dibandingkan bagian lamun pada bagian atas substrat.

\section{Konsentrasi Karbon Lamun}

Hasil pengukuran konsentrasi karbon lamun pada setiap stasiundidapatkan bahwa pada Stasiun 3 merupakan kandungan total karbon 
tersimpan tertinggi, yaitu total karbon sebesar $246,99 \mathrm{gC} / \mathrm{m}^{2}$. Jumlah berat karbon pada bagian daun sebesar 93,00 $\mathrm{gC} / \mathrm{m}^{2}$ dan berat karbon dari bagian rhizoma dan akar lamun ialah 153,99 $\mathrm{gC} / \mathrm{m}^{2}$. Pada Stasiun 2 terdapat total karbon dengan jumlah terendah, yaitu sebesar 145,59 $\mathrm{gC} / \mathrm{m}^{2}$. Jumlah bagian daun sebanyak 39,93 $\mathrm{gC} / \mathrm{m}^{2}$ dan berat bagian lainnya sebesar 105,66 $\mathrm{gC} / \mathrm{m}^{2}$. Pada Stasiun 1 jumlah total kandungan karbon ialah 169,66 $\mathrm{gC} / \mathrm{m}^{2}$, yakni pada bagian daun sebesar $44,37 \mathrm{gC} / \mathrm{m}^{2}$ dan pada bagian akar dan rhizoma sebesar $125,28 \mathrm{gC} / \mathrm{m}^{2}$. Salah satu fungsi lebih besarnya biomassa pada bagian bawah substrat pada lamun ialah agar lamun dapat menancap pada substrat lebih kuat[11]. Adapun nilai-nilai tersebut dapat dilihat pada Gambar 5.

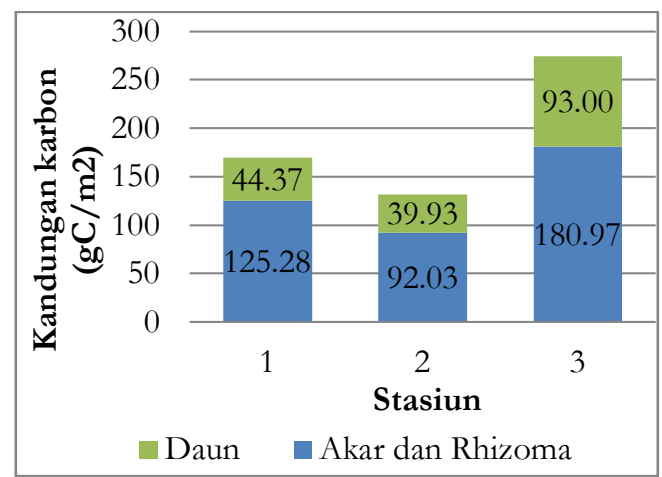

Gambar 5. Jumlah kandungan karbon PadaLamun $E$. acoroides yang dibagiatas 2 bagian yaitu Daun (aboveground) serta Akar dan Rhizoma(below ground).

\section{KESIMPULAN DAN SARAN}

\section{Kesimpulan}

Berdasarkan penelitian mengenai karbon tersimpan pada E. acoroides disimpulkan bahwapada Stasiun 3 nilai rata-rata penutupannya tertinggi, yaitu 96,67, sedangkan pada Stasiun 2 merupakan nilai rata-rata penutupan terendah, yakni $75 \pm 15 \%$.Pada Stasiun 3 nilai merupakan kerapatan tertinggi yaitu sebesar $216,67 \mathrm{ind} / \mathrm{m}^{2}$, sedangkan pada Stasiun 2 terdapat nilai terendah yakni sebesar $116,67 \mathrm{ind} / \mathrm{m}^{2}$.

Jumlah biomassa tertinggi terdapat pada Stasiun 3, yaitu berat total $1859 \mathrm{gbk} / \mathrm{m}^{2}$. Pada Stasiun 2 didapatkan jumlah biomassa terendah, yaitu dengan berat total $1101,03 \mathrm{gbk} / \mathrm{m}^{2}$. Pada
Stasiun 3 didapatkan hasil kandungan karbon tersimpan dengan jumlah tertinggi, yaitu total sebesar 246,99 $\mathrm{gC} / \mathrm{m}^{2}$. Hasil pada Stasiun 2 merupakan jumlah kandungan terendah, yakni dengan berat total sebesar $145,59 \mathrm{gC} / \mathrm{m}^{2}$.

\section{Saran}

Adapun saran yang dapat diberikan setelah dilakukannya penelitian ini antara lain pada penelitian selanjutnya dilakukan penambahan titik lokasi dengan harapan agar menjangkau lamun lebih luas. Peningkatan kesadaran masyarakat agar menjaga kelestarian ekosistem lamun perluditingkatkan dan dilaksanakan mengingat ekosistem lamun memiliki manfaat yang penting.

\section{UCAPAN TERIMAKASIH}

Penulis mengucapkan terimakasih kepada pihak Laboratorium Ekologi FMIPA UB yang telah mengizinkan dan membantu selama penelitian ini dilakukan. Ucapan terimakasih juga disampaikan kepada Bapak Umar dan temanteman yang telah membantu selama di lapangan.

\section{DAFTAR PUSTAKA}

[1] IPCC,"The Physical Science Basis. Contribution of Working Group I to the Fourth Assessment Report of the Intergovernmental Panel on Climate Change", 2007.

[2] T. Samiaji, "Upaya Mengurangi CO2 Di Atmosfer," Berita Dirgantara, vol. 10, no. 3, pp. 92-95, 2009.

[3] S. Sukandar and C. Satrya Utama Dewi, "Status padang lamun di Pulau Talango, Madura dan potensinya sebagai bahan baku bioaktif," Depik, vol. 6, no. 2, pp. 138-144, Aug 2017.

[4] Y. I. Graha, I. W. Arthana, and I. W. G. A. Karang, "Simpanan karbon padang lamun di kawasan pantai sanur, kota denpasar," ECOTROPHIC: Jurnal Ilmu Lingkungan 
(Journal of Environmental Science), vol. 10, no. 1, pp. 46-53, 2016.

[5] A. Rustam et al., "Peran Ekosistem Lamun Sebagai Blue Carbon Dalam Mitigasi Perubahan Iklim, Studi Kasus Tanjung Lesung, Banten," Jurnal Segara, vol. 10, no. 2, Nov 2015.

[6] KEPMENLH, "Kriteria Baku Kerusakan dan Pedoman Penentuan Status Padang Lamun",2004.

[7] M. H. Azkab, "Pedoman inventarisasi lamun," Oseana, vol. 24, no. 1, pp. 1-16, 1999.

[8] Helrich, K. 1990. "Method of Analysis of The Association of Official Analytical Chemists, (Fifteenth Edition)".

[9] Agus, F. Hairiah, K., Mulyani, A., and World Agroforestry Centre (ICRAF). "Pengukuran cadangan karbon tanah gambut", Bogor, Indonesia: World Agroforestry Centre (ICRAF), 2011.

[10] B.A.J. GosariandA.Haris, “Studi Kerapatan dan Penutupan Jenis Lamun di Kepulauan Spermonde". Jurnal Ilmu Kelautan dan Perikanan, 22 (3), 156-162, 2012.

[11] Supriadi, R.F. Kaswadji, D.G. Bengen, , and Hutomo, M.,. "Carbon Stock of Seagrass Community in Barranglompo Island, Makassar," vol. 19, no.1, pp. 1-10, 2014. 